Article

\title{
Enhancing Organizational Survivability in a Crisis: Perceived Organizational Crisis Responsibility, Stance, and Strategy
}

\section{JiYeon Jeong}

School of Advertising \& Public Relations, Hongik University, 2639 Sejong-ro, Jochiwon-eup, Sejong 30100, Korea; E-Mail: jyjeong@hongik.ac.kr; Tel.: +82-44-860-2499; Fax: +82-44-862-3490

Academic Editor: Giuseppe Ioppolo

Received: 22 June 2015 / Accepted: 13 August 2015 / Published: 25 August 2015

\begin{abstract}
For the purpose of enhancing organizational sustainability during a crisis, an organization takes a position in decision-making, how to respond toward its public, and that is supposed to determine which stance or tactic to employ. This study aims to examine whether publics' perceptions of organizational crisis responsibility affect their expectations that an organization should choose certain stances and strategies toward the public in a crisis. To address these concerns, an experiment was conducted. As the specific public of this research, health journalists were selected, since they affect public perceptions significantly and public opinion can ultimately put pressure on an organization. Results from an analysis of the experimental data with health journalists confirm that they expect a more accommodative stance/strategy when they perceive that the organization is highly responsible for a health-related crisis. Conversely, when the journalists perceive that an organization has a low level of responsibility for a crisis, they expect a more advocative stance/strategy. By taking into account the health journalists' expectations along with the needs of the organization, public relations practitioners are better able to make optimal decisions regarding their client organizations' adopted stance and strategy, and finally, enhance organizational sustainability in a crisis.
\end{abstract}

Keywords: organizational sustainability in a crisis; crisis responsibility; stance; strategy; contingency theory; public relations

\section{Introduction}

Sustainability is concerned with economic, social, and environmental effects of an organization in the long term, and organizations aim to maximize their absolute values by balancing people, planet, and 
profit. In order to enhance organizational sustainability, it is in the interest of an organization to understand what its public desires, expects, and needs to hear from the organization when it is facing a conflict, especially when it is apparent that harm to the public has occurred; by doing so, public relations practitioners can anticipate how the public is likely to react and know how better to position their client organizations to select appropriate crisis communication strategies, as well as to assess the potential utility of their various communication options. How people perceive the crisis situation, and especially how people perceive an organization's crisis responsibility, are critical elements in understanding crisis situations, and people's perceptions of crisis situations affect the organizational choice of strategies [1,2]. Because the public attributes some responsibility for the conflict to an organization, the organization's response is necessary in dealing with the conflict and, ultimately, in minimizing the harm from the conflict [3-6]. This study, therefore, aims to examine whether publics' perceptions of crisis responsibility affect their expectations that an organization should choose certain stances and strategies toward the public in certain circumstances. Based on the contingency theory of strategic conflict management, this study further asks if a public's perceptions of an organization's crisis responsibility can be a new contingency factor affecting their expectations of the organization's stance and strategy in a crisis, and finally contribute to organizational sustainability.

Few studies have examined the ways in which specific public perceptions of an organization's crisis responsibility affect the public's expectations of the organization's stance and strategy toward the public in conflict situations. As the specific public of this research, the researcher selected health journalists. Organizations that provide health-related services are crucial to public health, and public relations has an important role to play in helping such organizations achieve their goals. This is especially true in the midst of conflict situations. It is crucial to understand journalists' perceptions of the crisis, since they affect public perceptions so significantly and public opinion can ultimately put pressure on an organization [7]. In sum, for the purpose of enhancing organizational sustainability, this study examines the causal effects of public relations contingencies on an organization's stance and strategy toward the public through the lens of public perceptions of organizational crisis responsibility. To investigate these concerns, this study reports on an experiment conducted with health journalists. The study's findings should contribute to organizational sustainability, as well as the study of conflict management, and offer useful insights for public relations practitioners and health journalists.

\section{Literature Review}

\subsection{Stance}

The contingency theory of strategic conflict management explains an organization's position toward a public in a given time and situation as a stance, which is the key concept in understanding public relations practice [8]. Contingency theory suggests a wide range of possible stances along a continuum that an organization can take toward its public. The continuum ranges from pure advocacy to pure accommodation (see Figure 1). Advocacy refers to the degree to which organizations maintain standpoints favorable to themselves, rather than to the public. Accommodation refers to the degree to which organizations accept the public's standpoint or argument. Pure advocacy is characterized as an exclusively assertive argument in an organization's own interests, while pure accommodation is 
characterized as complete concession to the public [8]. Shin [9] elaborates further on advocacy as self-interest, and accommodation as concern for others. The stance moves along the continuum over time, depending on the circumstance: An organization positions itself flexibly somewhere between pure advocacy and pure accommodation, depending on the circumstances [8].

Pure Advocacy

\section{Pure Accommodation}

Figure 1. Continuum of Accommodation.

\subsection{Crisis Communication Strategy}

Recent studies in conflict management have integrated crisis response strategy frameworks into the contingency continuum. Research shows that different degrees of advocacy and accommodation result in different crisis communication strategies [10-12]. In other words, the researchers argued that, as the stances of an organization change, its strategies also move on the continuum from pure advocacy to pure accommodation. The most widely used crisis communication strategy approaches in conflict management have been Benoit's image repair theory and Coombs' situational crisis communication theory (see Figure 2). These two theories have provided the dominant paradigms for crisis communication strategy research in public relations $[13,14]$.

Benoit's image repair theory provides general principles that can be applied when developing and understanding how specific strategies can, and should, be used effectively. The theory has been examined primarily in the context of descriptive rhetorical case analyses and has largely focused on communication options. A recent study by Hwang and Cameron [11] applied Benoit's five strategies to contingency theory. In their experimental research, they utilized Benoit's five strategies to measure an organization's message strategy in crisis communication. Through factor analyses, they defined denial, evading responsibility, and reducing offensiveness as measurements for advocative strategy, and corrective action and mortification as measurements for accommodative strategy.

Coombs' [15] situational crisis communication theory has been developed by drawing upon the crisis response strategies articulated in Benoit's image repair theory. Coombs [16] asserts that crisis communication strategies should be arrayed along a continuum (with defensive and accommodative as the end points) and that different stages on the continuum require different crisis repair strategies. The term defensive that Coombs used is synonymous with the contingency theory's stance, advocacy. Coombs [2] argues that crises situations fall on a continuum ranging from weak personal control (less responsibility for the crisis) to strong personal control (more responsibility for the crisis). Coombs notes seven crisis response strategies that can be selected in a situation-based response to a crisis: attack the accuser, denial, excuse, justification, ingratiation, corrective action, and full apology. These crisis response strategies are characterized by their levels of acceptance of responsibility embodied in the response to the crisis [16,17]. Recent research has attempted to advance Coombs' crisis management strategy theory by integrating the strategy framework into the contingency continuum. Jin, Pang, and Cameron [18] focused their study of the SARS case on health-related and government aspects of the crisis and proposed modifying the strategy's framework. They suggested that an additional strategy, co-operation, be added to the continuum, as well as the re-ordering of corrective action and 
justification in Coombs' original crisis management communication strategies. Holtzhausen and Roberts [19] also suggested how contingency theory and Coombs' situational crisis communication theory offered a promising synthesis of ideas.

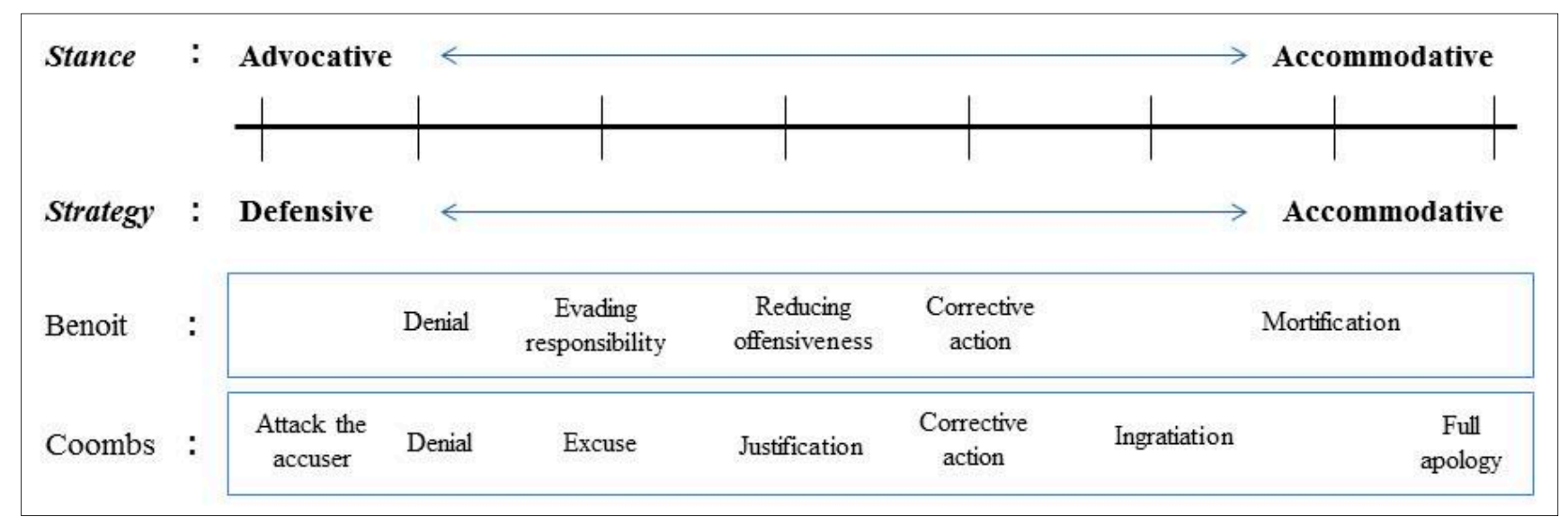

Figure 2. Stance and Crisis Communication Strategy.

\subsection{Contingent Factors to the Stance and Strategy}

The contingency theory argues that an organization's response depends on the situation, which, in turn, is dependent on the factors that affect one's stance. Cameron and his colleagues identified a number of factors that affect the stance an organization takes toward its public on a continuum from pure accommodation to pure advocacy [8,20-22]. The 86 contingent variables that contingency theory offered are divided into 11 categories on two dimensions of external and internal variables [20]. The external variables include threats, industry-specific environment, general political/social/cultural environment, external public, and the issue under question. The internal variables include an organization's characteristics, public relations department characteristics, dominant coalition characteristics, internal threats, individual characteristics, and relationship characteristics. Contingency variables are also categorized into predisposing and situational factors [21]. Predisposing variables, as existing variables, determine the stance of the organization before it goes into a situation dealing with a given public, while the combination and variability of situational variables may shift the stance of the organization over time. Well-supported predisposing variables include corporation size, corporate culture, corporation business exposure, public relations access to dominant coalition, dominant coalition's decision-making power and enlightenment, and individual characteristics of involved persons [21]. Situational variables are responsive to specific circumstances and settings, depending on whether the variables are powerful enough to change the predisposition to a particular stance on the continuum. The following are well-supported situational variables: urgency of situation, characteristics of external public's claims or requests, characteristics of external public, potential or obvious threats, balancing of interests, general public perception of the issue under question, corporation's public reputation, co-orientation of external public and corporation, feasibility of accommodation, characteristics of the public's actions, and potential cost or benefit for a corporation from choosing various stances [21]. 


\section{Hypotheses}

In response to the above literature, this study raises the question of whether public perceptions of an organization's crisis responsibility could be a contingent factor to the conflict continuum and resulting conflict management strategies. Because the public attributes some responsibility for the conflict to an organization, the organization's response is necessary in dealing with the conflict and, ultimately, in minimizing the harm from the conflict [3-6]. In other words, the stances and strategies of an organization are associated with the public attribution of responsibility. This study, therefore, aims to examine the causal effects of public relations contingencies on an organization's stance and strategy toward the public through the lens of public perceptions of organizational crisis responsibility. This study examines whether health journalists' perceptions of crisis responsibility affect their expectations that public relations practitioners should choose certain stances and strategies toward the public in certain circumstances. As Cameron and his colleagues [20] argued, contingent factors not only allow practitioners to monitor the environment in order to reach a stance, but also allow scholars and theorists to manage the factors in useful ways. The following hypotheses are suggested:

H1a. Health journalists' expectations of an organization's stance for a health-related crisis will be associated with their perceptions of the organization's responsibility for the crisis.

$H 1 b$. Health journalists will expect a more accommodative stance when they perceive that an organization bears a high level of responsibility for a health-related crisis.

H1c. Health journalists will expect a more advocative stance when they perceive that an organization bears a low level of responsibility for a health-related crisis.

Based on the reviewed literature, this study assumes that a perceived stance might produce a similar. directional crisis response strategy expectation. Thus the following hypotheses are proposed:

$H 2 a$. Health journalists' expectations of an organization's strategy for a health-related crisis will be associated with their perceptions of the organization's responsibility for the crisis.

$H 2 b$. Health journalists will expect a more accommodative strategy when they perceive that an organization bears a high level of responsibility for a health-related crisis.

H2c. Health journalists will expect a more advocative strategy when they perceive that an organization bears a low level of responsibility for a health-related crisis.

\section{Method}

\subsection{Procedure and Stimuli}

To test the proposed hypotheses, an experiment was conducted online utilizing Survey Monkey, an Internet tool for conducting, managing, and analyzing research. The experiment manipulated organizational crisis responsibility (high $v s$. low) and it was executed as within-subject factor in order to carry more statistical power and to require fewer subjects. The two dependent variables were health journalists' expectations of both an organization's stance and its strategy in a crisis.

The manipulation of an organization's responsibility in a crisis was created in the form of news stories by describing a fictitious pharmaceutical company's crisis, adverse effects of its drugs, and implicating either a high or low level of responsibility for the crisis. To avoid a confounding effect due to order 
effects in a repeated measures design, this study used counterbalancing [23]: Half of the participants received a treatment of high level of responsibility first, and the other half of the participants received a treatment of low level of responsibility first. This study accepts the assumption that random assignment will control the individual differences, which could possibly affect the dependent variables. Therefore, the order in which the participants complete the various treatments of the experiment was assigned using a random generator provided by the Internet tool. To address the possibility that sensitization or carry-over effects might threaten the validity of the factor, participants were also informed that they would have two separate series of two stories prior to being exposed to manipulation of an organization's responsibility.

\subsection{Participants}

Health journalists were recruited nationally. The researcher originally sent recruitment e-mails to 725 health journalists to screen for qualified participants who have worked in the healthcare field. Invitation e-mails were then sent to 68 people who indicated that they had worked in the healthcare or medical fields and that they were willing to participate in the study. The final number of health journalists participating in this study was 46. The sample size of participants was estimated using Power Analysis and Sample Size (PASS) software [24] (Power Analysis and Sample Size (PASS) software was used to estimate the sample size based on the following conditions: F tests (Repeated Measures Analysis of Variance), effect size $=0.5$, Alpha $=0.05$, and Power $=0.8$.), resulting in a required sample size of 34 . Participants received a $\$ 20$ gift card in thanks for their participation in this study.

\subsection{Measurements}

\subsubsection{Perception of an Organization's Crisis Responsibility}

Perception of an organization's crisis responsibility (perceived crisis responsibility) refers to the degree that participants assign responsibility for a crisis to an organization [25]. The operational definition of perceived crisis responsibility was a participant's perception of an organization's level of responsibility for a crisis, high vs. low. Crisis responsibility was assessed using two items adapted from Lee [26]: (a) "I think [Organization Name] should be blamed for the crisis," (b) "I think [Organization Name] should bear responsibility for the crisis." These items were measured on a seven-point Likert scale, ranging from 1 (strongly disagree) to 7 (strongly agree). The two items were strongly correlated, $r(92)=0.780, p<0.01$.

\subsubsection{Expectation of an Organization's Stance Responsibility}

Stance was operationalized as an organization's position toward the public in a crisis. Expectation of an organization's stance was operationalized as the degree to which participants in this study hold the opinion that an organization should assume a more accommodative or advocative position toward the public in a crisis. Participants' expectations regarding an organization's stance in a crisis communication were measured as participants' expectations of the degree of accommodation of the company. Ten stance measurement items were taken from [27]. Using the Jin and Cameron [27] measurement scale items as a template, this study asked participants, "Given the situation, [Organization Name] should 
," with participants responding to each of the 10 statements, the first cluster of which consisted of five items of action-based accommodations (e.g., yield to the public's demands, agree to try the solutions suggested by the public) and the second of which consisted of five items of qualified-rhetoric-mixed accommodations (e.g., express regret or apologize to the public, admit wrongdoing). These items were measured on a seven-point Likert scale, ranging from 1 (strongly disagree) to 7 (strongly agree). The scale reliability was Cronbach's $\alpha=0.941$.

\subsubsection{Expectation of an Organization's Strategy}

The operational definition of strategy was an organization's communicative plan of action toward the public in response to a crisis. Expectation of an organization's strategy was operationalized as the degree to which participants hold the opinion that an organization should assume a more accommodative or advocative communicative plan of action in response to a crisis. Participants' expectations regarding an organization's response strategy were measured with nine measurement items by selecting from the typologies of Benoit's [1] image repair strategies and Coombs' [5] crisis communication strategies. In order to determine constructs underlying the nine items of strategy, the researcher conducted factor analyses with both Varimax rotation and Direct Oblimin rotation. The nine items of strategy variables were identified as four accommodative strategies and five advocative strategies. They were measured on a seven-point Likert scale where 1 (strongly disagree) to 7 (strongly agree). Participants were asked "Given the situation, [Organization Name] should ," with participants responding to each of the following statements, the first cluster of which consisted of advocative strategy and the second of which consisted of accommodative strategy. Five advocative strategy items - attack the accuser, denial, scapegoat, excuse, and justification - were reverse coded. The reliability of the nine item scale resulted in a Cronbach's $\alpha=0.807$.

\subsection{Factor Analysis of Strategy Measurement Items}

In order to determine constructs underlying the nine items of strategy, the researcher conducted principal component analysis using a Varimax rotation. The factor analyses indicated two factors: accommodative strategy and advocative strategy. The two factors accounted for $61.48 \%$ of the variance and had eigenvalues greater than 1. A scree plot leveled off with the third factor, which indicates that examination of the scree plot supported the two-factor solution, as shown in Figure 3.

Communalities for the strategy measurement items ranged from 0.395 to 0.871 . Since communalities were greater than 0.3 , all the items were retained in the scale. Finally, based on these two factors, the nine items of strategy variables were identified as four accommodative strategies and five advocative strategies, as shown in Table 1. The four accommodative strategies were compensation, corrective action, apology, and full responsibility, while the five advocative strategies were attack the accuser, denial, scapegoat, excuse, and justification. The factor analyses with Direct Oblimin rotation also provided results consistent with the Varimax rotation analyses. The resulting subscales demonstrated an internal consistency coefficient (Cronbach's $\alpha$ ) of 0.884 (4 items for factor 1: accommodative strategy) and 0.714 ( 5 items for factor 2: advocative strategy). These results suggest that the 9-item instrument measuring strategy reflects satisfying internal consistency within each factor, and the subscales seemed reasonable and parsimonious. 
Table 1. Factor Loadings of Advocative Strategy and Accommodative Strategy.

\begin{tabular}{|c|c|c|c|}
\hline \multirow{2}{*}{\multicolumn{2}{|c|}{ Strategy Items }} & \multicolumn{2}{|c|}{ Factor } \\
\hline & & \multirow{2}{*}{$\begin{array}{c}\text { Advocative Strategy } \\
0.633\end{array}$} & \multirow[t]{2}{*}{ Accommodative Strateg. } \\
\hline Attack the accuser & $\begin{array}{l}\text { [Organization name] should claim that the FDA's policy and drug } \\
\text { approval processes are faulty. }\end{array}$ & & \\
\hline Scapegoat & $\begin{array}{l}\text { [Organization name] should claim that the product was administered by } \\
\text { health institutions incorrectly. }\end{array}$ & 0.708 & \\
\hline Justification & $\begin{array}{l}\text { [Organization name] should claim that there are many people suffering } \\
\text { from diseases that its drugs alleviate. }\end{array}$ & 0.745 & \\
\hline Compensation & $\begin{array}{l}\text { [Organization name] should offer compensation to patients' families for } \\
\text { the tragic recent situation. }\end{array}$ & & 0.87 \\
\hline Corrective Action & $\begin{array}{l}\text { [Organization name] should announce changes indicating its intentions } \\
\text { to prevent future deadly events. }\end{array}$ & & 0.872 \\
\hline
\end{tabular}

Note: 1. Factors extracted by principal components analysis and rotated by Varimax method; 2. Factor loadings less than 0.4 are omitted. 


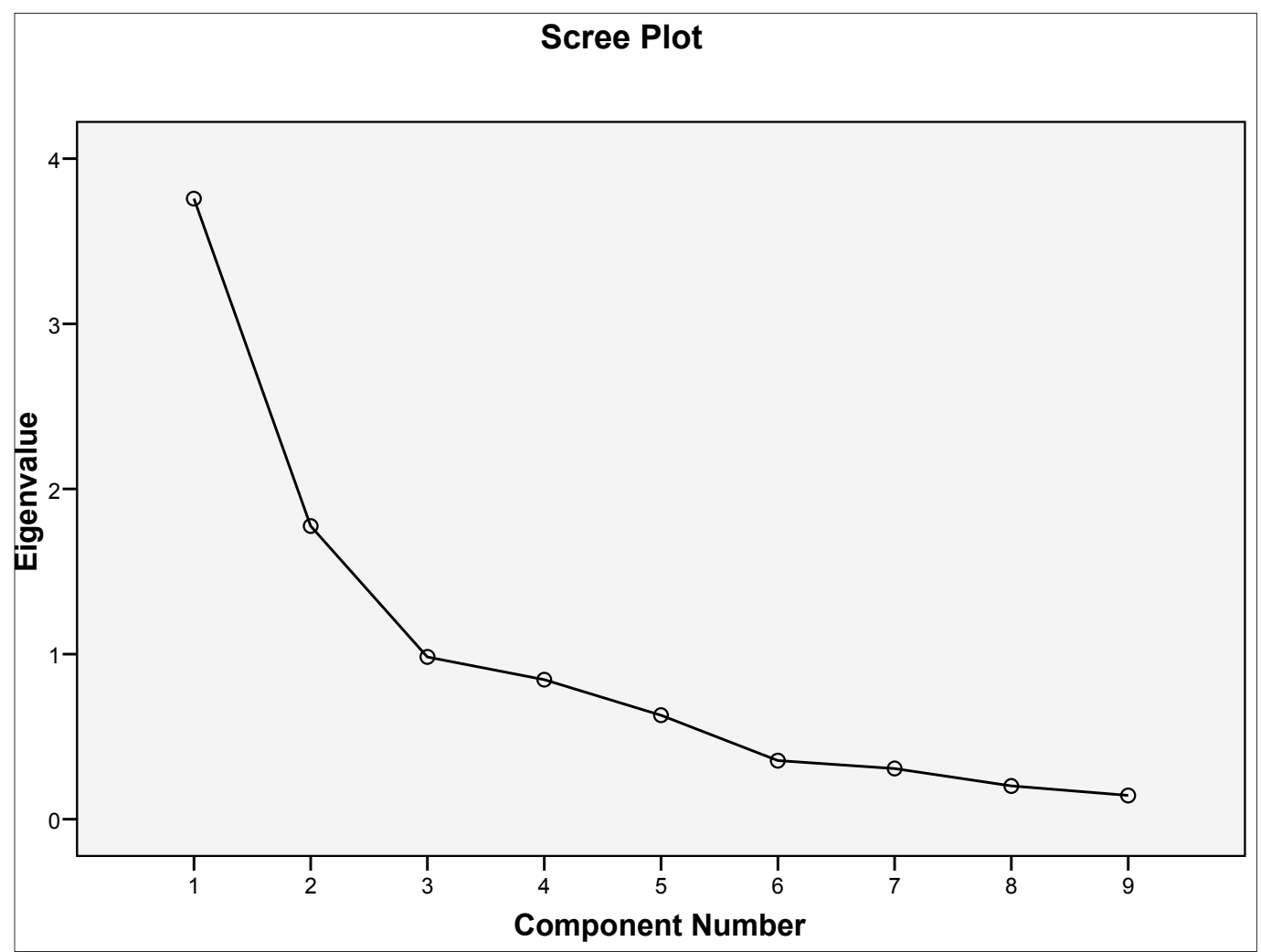

Figure 3. Scree Plot of Strategy. Note: Two factors have eigenvalues bigger than 1 (two-factor solution).

\subsection{Manipulation Checks}

A pretest was conducted to confirm that the independent variables were validly manipulated. The pretest of stimulus messages was given to 218 students from an undergraduate journalism class at a midwestern university, for which the students received extra credit. An independent-sample $t$-test was conducted to compare perceptions of responsibility in high responsibility and low responsibility conditions. The results showed that the manipulation of perceived crisis responsibility was successful at $p<0.001$ $(t(434)=6.77)$. The mean scores for the high level of responsibility and low level of responsibility within the pretest were $5.50(S D=1.22)$ and $4.66(S D=1.36)$, respectively. Manipulation checks were also conducted with health journalists. The results of the independent-samples $t$-test showed that the health journalists evaluated the organization's responsibility differently in high level of responsibility and low level of responsibility conditions, $M=5.12, S D=1.44 ; M=4.24, S D=1.27$, respectively, $t(90)=3.11$, $p=0.003$. These results suggest that the manipulation of levels of responsibility (high $v s$. low) does have an effect on a health journalist's perception of an organization's crisis responsibility.

\subsection{Data Analyses}

To test $H 1$ and $H 2$, the researcher divided health journalists' perceptions of an organization's crisis responsibility into two groups - perceived high vs. perceived low levels of responsibility - using a median split as a cut point. An independent-samples $t$-test was conducted to compare health journalists' expectations of an organization's stance and strategy in their perceptions of high-responsibility conditions as opposed to low-responsibility conditions. 


\section{Results}

The results of $H 1$ showed that the health journalists' expectations of an organization's stance for a crisis were associated with their perceptions of the organization's responsibility, $t(90)=6.28$, $p<0.001$. There was a significant difference in the scores for perceived high levels of responsibility $(M=5.50, S D=1.08)$ and perceived low levels of responsibility $(M=4.15, S D=0.81)$ conditions. These results indicate that health journalists' perceptions of an organization's crisis responsibility do have an effect on their expectations regarding the organization's stance. Specifically, the results suggest that when health journalists perceive that the organization is highly responsible for a health-related crisis, they expect the organization to take a more accommodative stance; conversely, the journalists expect a more advocative stance when they perceive that the organization has a low level of responsibility for a crisis. Therefore, Hla, Hlb, and Hlc were supported.

The results of $H 2$ showed that there was a significant difference in the scores for high responsibility $(M=5.50, S D=0.95)$ and low responsibility $(M=4.48, S D=0.74)$ conditions; $t(90)=5.71, p<0.001$. These results suggest that the health journalists' expectations regarding an organization's strategy for a crisis are demonstrably associated with their perceptions of the organization's crisis responsibility. Specifically, the results suggest that the health journalists expect a more accommodative strategy when they perceive that the organization is highly responsible for a health-related crisis. Conversely, when the journalists perceive that an organization has a low level of responsibility for a crisis, they expect a more advocative strategy. Therefore, $H 2 a, H 2 b$, and $H 2 c$ were supported.

In sum, the results indicate that health journalists' perceptions of organizational crisis responsibility affect their expectations that an organization should choose certain stances and strategies toward the public in a crisis. In other words, public perceptions of an organization's crisis responsibility could be a contingent factor to the conflict continuum and resulting conflict management strategies. The results provide empirical guidelines to practitioners for selecting appropriate crisis response strategies. An organization should choose accommodative stance/strategy including full responsibility, apology, corrective action, and compensation, when health journalists perceive that the organization is highly responsible for a health-related crisis. Conversely, when the journalists perceive that an organization has a low level of responsibility for a crisis, they expect a more advocative stance/strategy, and an organization is better to select an advocative stance/strategy including attacking the accuser, denial, scapegoating, excuse, and justification.

\section{Discussion}

The results of this study correspond to the existing literature in at least two ways. First, this study applies Coombs' [2] argument about the relationship between an organization's crisis responsibility and strategy to the contingency theory. Coombs argues that advocative strategies are more appropriate in situations of low responsibility for the crisis, whereas accommodative strategies are more appropriate under conditions of high responsibility for the crisis. Since this study not only confirms Coombs' argument regarding the impact of perceived crisis responsibility on strategy, but also explores the impact of perceived responsibility on stance, it contributes to the literature on contingency theory. From the perspective of health communication, these findings suggests that journalists have a pro-social attitude 
(they care about the welfare and rights of their audience) and seem to act in ways that they feel benefit their audience. Health journalists' subtle social activism could be attributed to their perceived adversarial role as journalists. Jeong, Len-Rios, Hinnant, and Cameron [28] explain that health journalists' adversarial role is related to their strong perceptions that health stories concern the reader's well-being. Second, the results of this study provide evidence for Pang's [12] three assumptions of conflict-positioning conceptualization based on "factor-stance-strategy". The results of this study confirm that the stance an organization takes is based on the contingency factors that affect this stance. This study also found that different stances lead to different crisis communication strategies; that is, as the stances of an organization change, its strategies move in conjunction with those stances, with the continuum extending from pure advocacy to pure accommodation. The validated relationships of "factor-stance-strategy" provide guidelines to practitioners for the use of crisis response strategy. Further research is warranted to determine the conceptual soundness and the utility of the guidelines established for selecting appropriate crisis response strategies. The researcher envisions the development of more diverse and dynamic crisis communication strategies. This research demonstrates nine strategy measurement items, drawn from the two most widely accepted crisis communication strategy theories in conflict management (Benoit's image repair theory and Coombs' situational crisis communication theory), to be reliable. Through factor analyses, the recommended nine strategy measurement items were found to have two clusters of accommodation and advocacy. The accommodative strategies include full responsibility, apology, corrective action, and compensation. The advocative strategies include attacking the accuser, denial, scapegoating, excuse, and justification. Based on these strategy measurements, the researcher provided an example of strategy measurement item guidelines for conflict management research for the selection or use of crisis response strategies (see Table 1). Since these measurement items were characterized within a health-related crisis context, further studies are recommended to refine the expression of the wording of these measurement items to reflect specific scenarios within the scope of a given study when applying them to future research projects. Researchers should also be aware that these guidelines are a recommendation, not a perfect recipe for success in crisis response strategy-related research. To better capture the strategy facets of the contingency continuum, further scale development and theory advancement efforts are needed.

The findings of this study point to important practical considerations for public relations practitioners engaged in health-related conflict management and provide them with better ways to lead their client organizations toward improved effectiveness. This research suggests that practitioners must value health journalists' perceptions along with the needs of their client organizations in order to manage a crisis effectively, because the viewpoints that journalists take toward the crisis in their coverage affect the opinions their audience forms about the crisis. In order to select an appropriate crisis response strategy through quick and accurate analysis, public relations practitioners need to be aware that tested strategies are available to them, and they need to have proven protocols in place for analyzing crisis situations. This research provides empirical guidelines for practitioners to help them keep health journalists' perceptions in mind when formulating crisis response strategies. In light of the importance of perceived crisis responsibility demonstrated in this study, practitioners need to explore reliable cues drawn from their field experiences to carefully estimate the level of responsibility the public will attribute to the organization.

Systematic approaches to comprehending contingency theory factors are crucial for analysis in crisis situations. However, practitioners should understand that the characteristic dynamics of the conflict will 
affect the organization's stance and strategy. The results and analyses of this research are solely based on a sample of health journalists and are thus limited. In order to reassess, corroborate, or elaborate on these research findings, further studies should be designed to replicate these findings and examining the following question: Do the findings from this study remain consistent when tested on differently-structured organizations; in the context of different types of crises; or with other sample groups, including journalists who work in other types of media?

\section{Conclusions}

In order to enhance organizational sustainability in a crisis, this study attempted to explore how health journalists' perceptions of an organization's responsibility during a health-related crisis affect their expectations of the organization's stance and strategy. To investigate these concerns, the researcher conducted an experiment with journalists currently working in the health/medical sector. The perception of crisis responsibility was highly supported by the experimental data of this research as a valid influence on the expectations of an organization's stance and strategy. The findings establish that health journalists' perceptions of an organization's crisis responsibility can be a new contingency factor affecting their expectations of the organization's stance and strategy in a crisis. In particular, health journalists' perceptions of an organization's crisis responsibility can be added to the list of contingency factors as a situational variable, one that is highly likely to influence how an organization relates to an external public. This new contingency factor will not only contribute to practitioners' ability to monitor the environment and to choose stances and strategies of communication to journalists, but will also extend the ability of scholars and theorists to manage the factors in enhancing organizational sustainability.

\section{Acknowledgments}

This work was supported by the Hongik University new faculty research support fund.

\section{Conflicts of Interest}

The author declares no conflict of interest.

\section{References}

1. Benoit, W.L. Image repair discourse and crisis communication. Public Relat. Rev. 1997, 23, 177-186.

2. Coombs, W.T. An analytic framework for crisis situations: Better responses from a better understanding of the situation. J. Public Relat. Res. 1998, 10, 177-191.

3. Benoit, W.L. Another visit to the theory of image restoration strategies. Commun. Q. 2000, 48, 40-44.

4. Brinson, S.; Benoit, W.L. The tarnished star: Restoring Texaco's damaged public image. Manag. Commun. Q. 1999, 12, 483-509.

5. Coombs, W.T. Protecting organization reputations during a crisis: The development and application of situational crisis communication theory. Corp. Reput. Res. 2007, 10, 163-176.

6. Len-Ríos, M.E.; Benoit, W.L. Gary Condit's image repair strategies: Determined denial and differentiation. Public Relat. Res. 2004, 30, 95-106. 
7. Sturges, D.L. Communicating through crisis: A strategy for organizational survival. Manag. Commun. Q. 1994, 7, 297-316.

8. Cancel, A.E.; Cameron, G.T.; Sallot, L.M.; Mitrook, M.A. It depends: A contingency theory of accommodation in public relations. J. Public Relat. Res. 1997, 9, 31-63.

9. Shin, J.H. Contingency theory. In Encyclopedia of Public Relations; Heath, R.L., Ed.; Sage Publications: Thousand Oaks, CA, USA, 2004; pp. 191-193.

10. Hwang, S.; Cameron, G.T. Public's expectation about an organization's stance in crisis communication based on perceived leadership and perceived severity of threats. Public Relat. Res. 2008, 34, 70-73.

11. Hwang, S.; Cameron, G.T. The estimation of a corporate crisis communication. Public Relat. Res. 2009, 35, 136-138.

12. Pang, A. Conflict Positioning in Crisis Management: Integrating Contingency Stance and Image Repair Strategies. Ph.D. Thesis, University of Missouri, Columbia, MO, USA, 2006.

13. Avery, E.J.; Lariscy, R.W.; Kim, S.; Hocke, T. A quantitative review of crisis communication research in public relations from 1991 to 2009. Public Relat. Res. 2010, 36, 190-192.

14. Jin, Y. Making sense sensibly in crisis communication: How publics' crisis appraisals influence their negative emotions, coping strategy preferences and crisis response acceptance. Commun. Res. 2010, 37, 522-552.

15. Coombs, W.T. Choosing the right word: The development of guidelines for the selection of the "appropriate" crisis response strategies. Manag. Commun. Q. 1995, 8, 447-476.

16. Coombs, W.T. Ongoing Crisis Communication: Planning, Managing, and Responding; Sage Publications: Thousand Oaks, CA, USA, 1999.

17. Coombs, W.T. Crisis management: A communicative approach. In Public Relations Theory II; Botan, C.H., Hazleton, V., Eds.; Lawrence Erlbaum Associates: Mahwah, NJ, USA, 2006; pp. 171-197.

18. Jin, Y.; Pang, A.; Cameron, G.T. Strategic communication in crisis governance: Singapore's Management of the SARS crisis. Cph J. Asian Stud. 2006, 23, 81-104.

19. Holtzhausen, D.R.; Roberts, G.F. An investigation into the role of image repair theory in strategic conflict management. J. Public Relat. Res. 2009, 21, 165-186.

20. Cameron, G.T.; Cropp, F.; Reber, B.H. Getting past platitudes: Factors Limiting accommodation in public relations. J. Commun. Manag. 2001, 5, 242-261.

21. Cancel, A.E.; Mitrook, M.A.; Cameron, G.T. Testing the contingency theory of accommodation in public relations. Public Relat. Res. 1999, 25, 171-197.

22. Shin, J.H.; Cameron, G.T.; Cropp, F. Occam's razor in the contingency theory: A national survey on 86 contingent variables. Public Relate. Res. 2004, 32, 282-286.

23. Reeves, B.; Geiger, S. Designing experiments that assess psychological responses. In Measuring Psychological Responses to Media; Lang, A., Ed.; LEA: Hillsdale, NJ, USA, 1994; pp. 165-180.

24. PASS 14. Available online: http://www.ncss.com/software/pass/ (accessed on 13 August 2015).

25. Coombs, W.T.; Holladay, S.J. An extended examination of the crisis situations: A fusion of the relational management and symbolic approaches. J. Public Relat. Res. 2001, 13, 321-340.

26. Lee, B.K. Audience-oriented approach to crisis communication: A study of Hong Kong consumer's evaluation of an organizational crisis. Commun. Res. 2004, 31, 600-618. 
27. Jin, Y.; Cameron, G.T. Scale development for measuring stance as degrees of accommodation. Public Relat. Res. 2006, 32, 423-425.

28. Jeong, J.Y.; Len-Rios, M.; Hinnant, A.; Cameron, G.T. Exploring Health Journalists' Professional Role Conceptions: A Comparative Analysis Emphasizing the Nature of Newspaper Journalism; Association for Education in Journalism and Mass Communication: Boston, MA, USA, 2009.

(C) 2015 by the authors; licensee MDPI, Basel, Switzerland. This article is an open access article distributed under the terms and conditions of the Creative Commons Attribution license (http://creativecommons.org/licenses/by/4.0/). 